\title{
Testing the volatility spillover between crude oil price and the U.S. stock market returns
}

\author{
Mehmet Kondoz $^{a^{*}}$, Ilhan Bora ${ }^{\mathrm{b}}$, Dervis Kirikkaleli ${ }^{\mathrm{c}}$, and Seyed Alireza Athari ${ }^{\mathrm{d}}$
} \author{
Cyprus, TR-10 Mersin, Turkey
}

${ }^{a}$ Department of Economics, Girne American University, Faculty of Business, T.R.N.C, Mersin 10, Turkey

${ }^{b}$ Faculty of Business, Cyprus Science University, Kyrenia, Northern Cyprus., TR-10 Mersin, Turkey

${ }^{c}$ European University of Lefke, Department of Banking and Finance, Faculty of Economic and Administrative Science, Lefke, Northern

dDepartment of Banking and Finance, Girne American University, Northern Cyprus, TR-10 Mersin, Turkey

\section{A B S T R A C T}

\begin{abstract}
The study aims to examine the volatility transmission between the West Texas Intermediate (WTI) crude oil price returns and the U.S. stock market (S\&P500 index) returns for the period 2006-2016. In the empirical analyses, univariate GARCH and multivariate GARCH (BEKK-GARCH) models are employed to investigate potential volatility spillover effect of crude oil price returns on the S\&P500 index returns or vice versa. The results of GARCH methods reveal that (i) volatility spillover effect of S\&P500 index returns on the crude oil returns is more significant than the volatility spillover effect of crude oil on the S\&P500 index returns by using univariate GARCH model; and (ii) there is a one way volatility spillover effect that runs from S\&P500 index returns to crude oil returns when we apply multivariate BEKK-GARCH model. These findings have implications for investors and oil-stock portfolio holders for their portfolio decisions in order to manage their risks on their international investments. Further, crude oil investment participants should consider the changes in U.S. stock market index returns in order to predict the expected volatility in the crude oil returns.
\end{abstract}

\section{Introduction}

Over the last three decades, the integration of financial markets has considerably increased globally and the borders of financial markets have become less pronounced with international markets. As a result of these integrations, the exposure of domestic financial markets to international financial market crises risks has increased. According to Karunanayake et al. (2009), cross-market volatility spillover (transmission of information across different markets) had increased among four major stock markets (U.S., Australia, Singapore and the U.K.) during the 2008 global crisis. They found that the volatility in the U.S. stock market had significantly affected the other major stock markets. Hence, in assessing the behavior of domestic financial market, we must consider the effect of international financial markets in addition to domestic macroeconomic news.

* Corresponding author.

E-mail address: mehmet.kondoz@creditwestbank.com (M. Kondoz) 
The commodities are another markets where we can see the effects of globalization. The commodity market experienced a huge amount of investment flow from equity portfolio investors in the 1990s. Stoll and Whaley (2009) argued that diversifying investment portfolios with the inclusion of commodity assets has become common since 1998. With the increasing amount of investment diversifications and Commodity Futures Modernization Act (CFMA-20001) in 2000, commodities have become "financialized" and this caused commodities to become correlated with each other and as well as with equity markets. Büyükşahin and Robe (2012) found that the correlation between commodity and equity markets has substantially increased after post- subprime mortgage financial crisis in 2008. Many other researchers such as Creti et al. (2013), Lombardi and Ravazzolo (2013) provided supportive evidence for this correlation and suggest investors to consider this linkage (which is likely to have created a volatility spillover from equities to commodities or vice versa) for formulating their investment decisions.

In this study, we focused on the world's most actively traded commodity which is crude oil. Crude oil has a very key position in the expanding global economy since it is the main energy source used for industrial activities, transportation, heating, etc. Thus, crude oil prices have direct or indirect effects on countries' economic activities. Even though the effects of crude oil on economies can vary due to the factors (1) oil-importing or exporting country (2) developed or developing country (3) the presence of alternative energy sources; the factors such as globalization, international trade, technology and crossborder financial integration are the main reasons of crude oil direct and indirect effects.

Various studies examined that the fluctuations occurred in the crude oil prices lead to significant ramifications on many macroeconomic variables (e.g., inflation, interest rates, stock market). For instance, the volatility in crude oil prices has an impact on the growth and productivity which also leads to fluctuations in the business cycle according to the study of (Olson, 1988). Burbidge and Harrison (1984) observed that the U.S. and Canadian aggregate prices are significantly affected by the crude oil prices. Cunado and De Gracia (2003) studied the effect of crude oil prices on inflation and industrial production indices for 15 European countries. The results indicated that oil prices have permanent impacts on inflation and asymmetric effects on production growth rates. Jacquinot et al. (2009) concentrated on Euro area and found supportive evidence that change in crude oil prices is one of the significant determinants of the inflation rate in the short-run.

On the other hand, Chen et al. (2014) argued that there are two major deficiencies in researching the oil price shocks throughout the literature. First; many research papers assumed that the crude oil prices are exogenous variable, but have not considered the volatility transmission effect that might be from economic activities to crude oil prices. Second; the recent studies concluded that the underlying causes of the crude oil price shocks is crucial to know since different originated shocks in the oil market have diverse impacts on stock markets and thus this determines the nexus among crude oil prices and stock market prices (Killian \& Park, 2009; Ciner, 2013). Due to the complexity of the commodity markets as we have mentioned earlier, crude oil prices can be determined not only by oil-supply and oil-demand information but also by the economic activities and financial markets.

Due to the interdependent and complex nature of the commodity and equity markets, the evaluation of volatility spillover has begun to be considered as an important finance application for investors and portfolio managers. Investors must intensify their vigilance on the movement of not only financial markets but also commodity markets (which are believed to be more interrelated) in order to plan their global investment strategies more accurately. The primary objective of this paper is to examine the volatility spillover among the crude oil price returns and the U.S. stock market returns by using recent time period

\footnotetext{
${ }^{1}$ Commodity Futures Modernization Act of 2000 (CFMA-2000) was signed into law by former President Clinton in order to modernize the regulatory and managerial roles of the Commodity Futures Trading Commission (CFTC) and the Securities and Exchange Commission (SEC). These new regulations had great impact on the derivatives and commodities markets (Kloner, 2001).
} 
compared to the other research papers. We consider the S\&P500 index in U.S. stock market which is a leading indicator of the economy. We find the best mean-variance equations of both time periods before employing the univariate and bivariate BEKK-GARCH models. With the methodology that we employed, we discovered that there is a volatility transmission running from S\&P500 index to the crude oil returns. This evaluation provides new evidence with recent collected data, and this finding can be used by investors and oil-stock portfolio holders on their international investments.

\section{Literature Review}

The relationship between crude oil and stock markets has been studied in various numbers of research papers. Jones and Kaul (1996) examined one of the first studies on testing the impact of oil price shocks on international stock markets. In their study, they considered the stock markets of the U.K., the U.S.A., Japan and Canada and the findings implied that the reactions of stock markets in Canada and the U.S.A were significant to the oil price shocks. Sadorsky (1999) showed any changes in oil prices directly affecting the U.S. stock markets and have asymmetric effects on the economy by using a VAR model; pointing out that oil price volatility gives significant explanations about stock market returns. In addition to these findings, the International Monetary Fund (2000) announced that a US\$5 per barrel price rising had great impacts on the state of the economy and this leads to reduction of global economic growth by $0.3 \%$ in the following years. Ciner (2001) employed non-linear causality tests in order to obtain shock transmission between the crude oil and stock market returns. The empirical results showed; (1) there is a volatility effect running from crude oil to stock market returns and (2) stock market returns also have impacts on crude oil futures. On the other hand, some studies concluded no relationship among oil price changes and stock market performance (Cong et al., 2008; Jammazi \& Alouli, 2010).

A number of studies have also investigated the impact of crude oil price on stock market prices by considering different stock market indices. El-Sharif et al. (2005) showed that the stock returns earned by U.K.-listed oil and gas companies are significantly impacted by the fluctuations of the crude oil prices. Furthermore, Arouri and Nguyen (2010) found evidence that the changes in oil price are positively affecting the returns of five European sector indices namely Financials, Oil and Gas, Industrials, Basic Materials, and Consumer Services and they also found negative effects of oil price volatility on Automobile and Parts, Food and Beverages, Health Care and Technology sectors. Similarly, Malik and Ewing (2009) studied the nexus between crude oil prices and U.S stock market indices by employing the BEKK parameterization of multivariate GARCH model. They concluded that there was a strong evidence of volatility spillover between oil prices and five different U.S. stock market indices which are health care, technology, industrials, financials and consumer services.

Depending on the focus and interest of our study, some other research papers which employed multivariate GARCH models in their studies are as follows. Ågren (2006) considered BEKK-GARCH model for the nexus between stock markets and crude oil prices and concluded that there was a strong evidence of volatility transmission between selected stock markets (Japan, U.K, Sweden and Norway) and crude oil. The results also revealed country-specific shocks were more substantial than oil shocks. By applying the same methodology used in Ågren's study (Ågren, 2006), Malik and Hammoudeh (2007) found significant volatility spillover between the U.S. stock market and crude oil for the period 1994-2001. They also examined in their study that the stock market in Bahrein, Kuwait, and Saudi Arabia were also triggered by the volatility of crude oil prices. Anand et al. (2014) by applying a bivariate BEKK-GARCH model found that the fluctuations in the crude oil price returns could impact on the volatility of Indian stock market returns. They also added that the spotted volatility spillover was more significant during the postfinancial crises period. Gomes and Chaibi (2014) employed the same method used in the study of Anand et al. (2014) and they showed the existence of volatility transmission and bi-directional spillover effect between oil prices and some frontier stock markets. Their findings indicated that spillovers were more often observable from oil to stock markets rather than from stock markets to crude oil. Khalfaoui et al. (2015) performed an econometrics analysis by combining multivariate GARCH models with wavelet 
multiresolution analysis. The results showed that the crude oil prices and G-7 stock markets were affected by their own volatilities and they found an indirect volatility transmission running from oil prices to stock market prices and vice versa. By contrast, Wei and Chen (2014) examined the volatility spillover between crude oil and U.S. stock market by employing multivariate BEKK-GARCH methodology. Their findings showed that crude oil spot returns were affected by the volatility of the U.S. stock market returns. Chen et al. (2014) concluded that financial shocks determined the oil prices and suggested policymakers to consider fluctuations in financial market conditions when examining the effects of oil price shocks on economic activities. Nazlioglu et al. (2015) examined the causality among the oil prices and financial stress and reported volatility spillover causation from oil prices to financial stress before the crisis in 2008 and detected causation from financial stress to oil prices after the 2008 recession period. Özer (2017) employed VAR-GARCH methodology to examine the relationship between oil price returns and stock market returns. The result indicated that the fluctuations of U.S. stock market returns have significant impact on oil price returns.

In the literature, we generally observed that volatility spillover effects are examined only by considering one methodology. There are no significant studies which examined the nexus between the crude oil and the U.S. stock market by performing two volatility spillover techniques. In this study, we present results not only from one methodology, but also we offer more findings obtained by two approaches. Besides, a long time period including recent data is selected for this study which makes it more up-to-date compared to other studies.

\section{Data and Models}

For performing the empirical analysis, this study considers the closing prices of American stock market S\&P500 index and the WTI crude oil prices. Historical data of both S\&P500 index returns and crude oil price returns are collected for 10 year time periods from 2006 to 2016 by removing the non-trading dates to increase the study's consistency. For investigating the possible volatility spillover effect between the variables, this study attempts to identify the mean and variance equations of each variable. We selected ARMA $(1,1)$ for S\&P500 index returns as the best possible fitted mean equation model due to the lowest AIC value compared to other AR, MA, and ARMA models with different orders.

$$
r_{s, t}=c_{s}+\beta_{1} r_{s, t-1}+\gamma_{1} \varepsilon_{s, t-1}+\varepsilon_{s, t}
$$

where $r_{s, t}$ is the conditional mean equation of S\&P500 index at time $t, r_{s, t-1}$ is lagged return, $\varepsilon_{s, t}$, and $\varepsilon_{s, t-1}$ are error terms and, $\beta$ and $\gamma$ are the parameters of AR and MA models respectively.

Similarly, the ARMA $(1,1)$ is selected as the best possible fitted model for the crude oil returns due to the lowest AIC value compared to other AR, MA, and ARMA models with different orders.

$$
r_{o, t}=c_{o}+\beta_{1} r_{o, t-1}+\gamma_{1} \varepsilon_{o, t-1}+\varepsilon_{o, t}
$$

where $r_{o, t}$ is return equation of crude oil (between time t-1 and t), $r_{o, t-1}$ 's the lagged return on crude oil returns, $\varepsilon_{o, t}$ and $\varepsilon_{o, t-1}$ are the error terms, and $\beta$ and $\gamma$ are the parameters.

Conditional variances of all variables are identified by using GARCH process. According to the GARCH model of Bollerslev (1986), the simple GARCH $(1,1)$ process often provides good fitted conditional variance equation for the time series models. Therefore, $\operatorname{GARCH}(1,1)$ model is applied on both variables. Table 1 shows the information criteria and log likelihood results obtained by applying the ARMAGARCH model to both log return time series. The mean-variance equations' coefficients are also obtained significant. The fitted mean-variance equations for both S\&P500 index and crude oil are presented in Table 1 as follows. 
Table 1

Mean - variance equation results (S\&P500 Log Returns)

\begin{tabular}{|c|c|c|c|c|}
\hline & AIC & $\mathrm{SC}$ & Log Likelihood & Mean - Variance Coefficients \\
\hline $\begin{array}{l}\text { ARMA }(1,1) \\
\operatorname{GARCH}(1,1)\end{array}$ & -6.400 & -6.386 & 8034.962 & $\begin{array}{ll}\text { SG } & \text { SG }\end{array}$ \\
\hline \multicolumn{5}{|c|}{ Crude Oil Log Returns } \\
\hline & AIC & $\mathrm{SC}$ & Log Likelihood & Mean - Variance Coefficients \\
\hline $\begin{array}{l}\operatorname{ARMA}(1,1) \\
\operatorname{GARCH}(1,1)\end{array}$ & -4.972 & -4.965 & 6244.130 & $\mathrm{SG}$ \\
\hline
\end{tabular}

The mean and variance equation of S\&P500 index are presented as follows.

$$
r_{s, t}=0.000617+0.740678 r_{s, t-1}-0.798459 \varepsilon_{s, t-1}+\varepsilon_{s, t}
$$

where $\varepsilon_{s, t}=\sigma_{s, t} z_{s, t}$

$$
\sigma_{s, t}^{2}=0.00000241+0.105569 \varepsilon_{s, t-1}^{2}+0.875881 \sigma_{s, t-1}^{2}(0.105569+0.875881<1) .
$$

The mean and variance equation - Crude Oil presented as follows,

$$
r_{o, t}=0.000246-0.793385 r_{o, t-1}+0.768412 \varepsilon_{o, t-1}+\varepsilon_{o, t},
$$

where $\varepsilon_{o, t}=\sigma_{o, t} z_{o, t}$,

$$
\sigma_{o, t}^{2}=0.00000448+0.074254 \varepsilon_{o, t-1}^{2}+0.919162 \sigma_{o, t-1}^{2}(0.074254+0.919172<1)
$$

\section{Empirical Analysis}

Table 2 shows the descriptive statistics for the daily log returns of both variables. The descriptive statistics show that the sample mean values for the S\&P500 index and crude oil are $+0.020 \%$ and $-0.019 \%$ respectively. In addition, it shows that the highest daily returns of S\&P500 index and Crude oil are $10.96 \%$ and $21.28 \%$ and the lowest returns are $-9.470 \%$ and $-13.065 \%$, respectively. Moreover, it shows that the standard deviation values for S\&P500 index and crude oil are $1.311 \%$ and $2.405 \%$ which imply that crude oil returns have higher variability compared to the than S\&P500 index returns over 2006-2016.

Table 2

Descriptive statistics (2006-2016)

\begin{tabular}{ccc}
\hline Statistics indicators & S\&P500 index & Crude oil \\
\hline Mean & 0.000203 & -0.000190 \\
Median & 0.000730 & 0.000325 \\
Maximum & 0.109572 & 0.212765 \\
Minimum & -0.094695 & -0.130654 \\
Std. Dev. & 0.013110 & 0.024049 \\
Skewness & -0.327644 & 0.244892 \\
Kurtosis & 13.24772 & 9.238533 \\
Jarque-Bera & 11027.80 & 4095.399 \\
\hline
\end{tabular}

Fig. 1 and Fig. 2 present the time plots of daily closing prices and daily log returns for S\&P500 index and crude oil respectively. Focusing on the daily closing prices time plot, it evidently shows the significant negative effect of global financial crisis in 2008 and 2009 on closing prices of both variables. However, the magnitude of effect of financial crisis is relatively more on crude oil closing prices. In this period, the price returns of both variables are so volatile. After the global financial crisis period, Figures 
shows that the positive the co-movements between two times series variables except a negative co-movement in 2014. After 2014, a negative correlation is observed between two closing price time series since the oil prices significantly decreased from $\$ 107$ to around $\$ 38$ per barrel whereas the stock index prices continued to increase from $\$ 1,963$ up to $\$ 2,078$ in the same time interval (from 20/06/2014 to 29/12/2016).
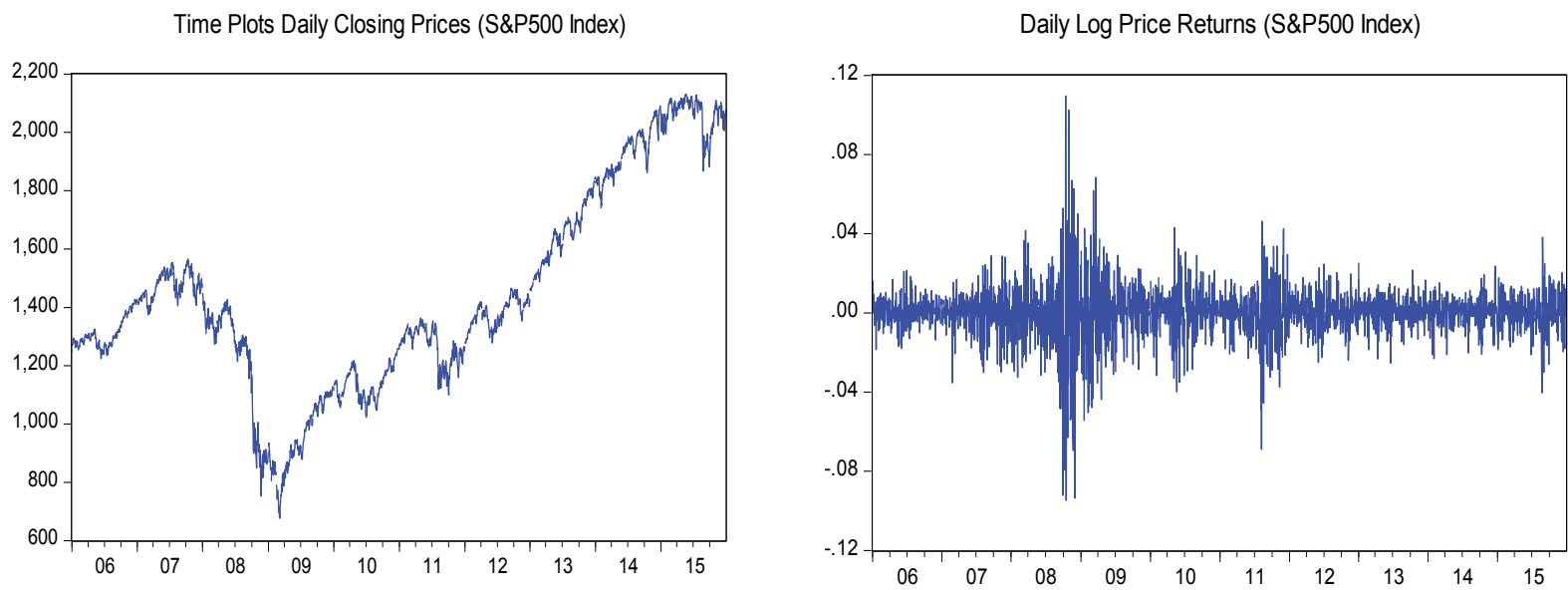

Fig. 1. Time Plots for S\&P500 Index

Time Plots Daily Closing Prices (Crude Oil Prices)

Daily Log Price Returns (Crude Oil Prices)
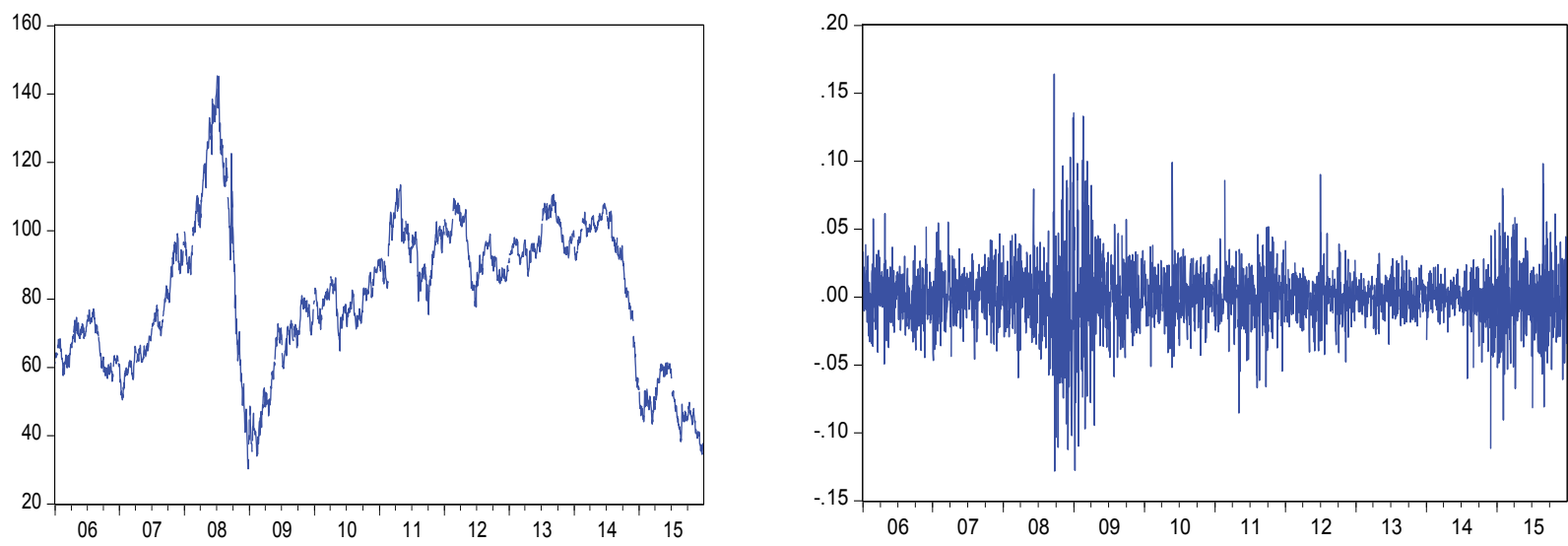

Fig. 2. Time Plots for Crude Oil

\subsection{Univariate GARCH Method - Volatility Spillover Effect Results}

For testing the potential volatility spillover effect from crude oil returns to the S\&P500 index returns, the standardized squared residuals of crude oil returns which is estimated with ARMA $(1,1)$ - GARCH $(1$, 1) equation is used as an exogenous variable in variance equation of S\&P500 index returns. The findings on Table 3 show that S\&P500 index returns is significantly affected by its own volatility and affected by specific volatility that comes from crude oil returns. A positive volatility spillover is detected from crude oil returns to S\&P500 index returns with volatility of $0.164 \%$ (variance of $2.68 \times 10^{-6}$ as can be shown in Table 3).

The next step is to examine the possible reverse spillover effect that might be from the S\&P500 index returns to crude oil returns. The standardized squared residuals of S\&P500 index which is estimated with ARMA $(1,1)$ - GARCH $(1,1)$ equation is used as an exogenous variable in variance equation of crude oil returns. Table 4 shows positive volatility spillover from S\&P500 index returns to crude oil returns with volatility of $0.327 \%$ (variance of $1.07 \times 10^{-5}$ as shown in the table). Thus, these results indicates that the volatility effects of S\&P500 index on the crude oil returns is more significant than the volatility effects of crude oil returns on the S\&P500 index returns. 
Table 3

Univariate GARCH - Volatility Spillover Effect (Crude oil to S\&P500 index)

\begin{tabular}{|c|c|c|c|c|}
\hline Variable & Coefficient & Std. Error & z-Statistic & Prob. \\
\hline $\mathrm{C}$ & $0.000686^{* *}$ & 0.000145 & 4.730471 & 0.000 \\
\hline $\operatorname{AR}(1)$ & $0.746315^{* *}$ & 0.089404 & 8.347689 & 0.000 \\
\hline $\operatorname{MA}(1)$ & $-0.802515 * *$ & 0.078625 & -10.2068 & 0.000 \\
\hline \multicolumn{5}{|c|}{ Variance Equation } \\
\hline $\mathrm{C}$ & $1.62 \mathrm{E}-07$ & $4.41 \mathrm{E}-07$ & 0.366583 & 0.7139 \\
\hline $\operatorname{RESID}(-1)^{\wedge} 2$ & $0.095085 * *$ & 0.00917 & 10.36925 & 0.000 \\
\hline GARCH(-1) & $0.88061 * *$ & 0.010439 & 84.35807 & 0.000 \\
\hline$(\text { RESIDC.Oil) })^{\wedge}$ & $2.68 \mathrm{E}-06^{* *}$ & $5.08 \mathrm{E}-07$ & 5.279524 & 0.000 \\
\hline \multicolumn{5}{|c|}{ Diagnostic Results } \\
\hline R-squared & 0.008481 & & dependent var. & 0.000197 \\
\hline Adjusted R-squared & 0.007689 & & ependent var. & 0.013108 \\
\hline S.E. of regression & 0.013058 & & info criterion & -6.4092 \\
\hline Sum squared resid & 0.427301 & & arz criterion & -6.39294 \\
\hline Log Likelihood & 8047.337 & & n-Quinn criter & -6.4033 \\
\hline Durbin-Watson stat & 2.100289 & & & \\
\hline Inverted AR roots & 0.75 & & & \\
\hline Inverted MA roots & 0.8 & & & \\
\hline
\end{tabular}

Table 4

Univariate GARCH - Volatility Spillover Effect (S\&P500 index to Crude oil)

\begin{tabular}{|c|c|c|c|c|}
\hline Variable & Coefficient & Std. Error & z-Statistic & Prob. \\
\hline AR(1) & -0.863266 & 0.097886 & -8.81906 & 0 \\
\hline $\mathrm{MA}(1)$ & 0.8405 & 0.104377 & 8.052519 & 0 \\
\hline \multicolumn{5}{|c|}{ Variance Equation } \\
\hline $\mathrm{C}$ & $-9.39 \mathrm{E}-07$ & $1.43 \mathrm{E}-06$ & -0.65476 & 0.5126 \\
\hline $\operatorname{RESID}(-1)^{\wedge} 2$ & 0.081165 & 0.009146 & 8.874794 & 0 \\
\hline GARCH(-1) & 0.900282 & 0.010765 & 83.6314 & 0 \\
\hline$($ RESIDC.Oil)^2 & $1.07 \mathrm{E}-05$ & $1.44 \mathrm{E}-06$ & 7.445554 & 0 \\
\hline \multicolumn{5}{|c|}{ Diagnostic Results } \\
\hline R-squared & 0.002246 & \multicolumn{2}{|c|}{ Mean dependent var. } & -0.0002 \\
\hline Adjusted R-squared & 0.001848 & \multicolumn{2}{|c|}{ S.D. dependent var. } & 0.024044 \\
\hline S.E. of regression & 0.024022 & \multicolumn{2}{|c|}{ Akaike info criterion } & -4.98293 \\
\hline Sum squared resid & 1.44667 & \multicolumn{2}{|c|}{ Schwarz criterion } & -4.969 \\
\hline Log Likelihood & 6257.087 & \multicolumn{2}{|c|}{ Hannan-Quinn criter } & -4.97787 \\
\hline Durbin-Watson stat & 2.030701 & & & \\
\hline Inverted AR roots & 0.86 & & & \\
\hline Inverted MA roots & 0.84 & & & \\
\hline
\end{tabular}

\subsection{Bivariate BEKK-GARCH Method-Spillover Effect Results}

Considering the international literature in recent years, multivariate GARCH models are more popular than univariate methods, especially when we want to analyze the volatility transmission among different time series. This method provides a conditional variance matrix system which is basically a simultaneous equation for time series rather than a two-step approach as we followed while we employ univariate GARCH method. For this reason, we also performed BEKK (Baba et al., 1990) parameterization of the multivariate GARCH (MGARCH) method in this study. The following steps are for the BEKKMGARCH by using GARCH $(1,1)$ model, and it is presented with its descriptions and specifications.

where

$$
H_{t}=C_{0} C^{\prime}{ }_{0}+A \varepsilon_{t-1} \varepsilon^{\prime}{ }_{t-1} A^{\prime}+B H_{t-1} B^{\prime}
$$

- $\quad H_{t}$ is $2 \times 2$ conditional variance and covariance matrix for stock returns and crude oil returns which can be shown as follows, 
$H_{t}=\left[\begin{array}{cc}h_{o, t} & h_{o s, t} \\ h_{s o, t} & h_{s, t}\end{array}\right] \quad h_{o, t}=$ variance of crude oil returns, $h_{s, t}=$ variance of stock returns, and $h_{o s, t}=h_{s o, t}=$ covariance of crude oil and stock returns.

- $C_{0}$ is $2 \times 2$ upper triangular matrix which contains constants where matrix multiplication of $C_{0}$ allow us to obtain positive definite $H_{t}$ matrix. The constants are denoted as $\gamma$ (gamma)

$C_{0}=\left[\begin{array}{cc}\gamma_{o} & \gamma_{o s} \\ 0 & \gamma_{s}\end{array}\right]$

- $\quad A$ and $B$ are $2 \times 2$ parameter matrices. Matrix $A$ shows how historical squared errors $\left(\varepsilon_{t-1}\right)$ affects the $H_{t}$, and $B$ indicates how past conditional variance-covariances $\left(H_{t-1}\right)$ affects the current $H_{t} . \alpha$ and $\beta$ are symbolized for the matrices $A$ and $B$, respectively.

$A=\left[\begin{array}{cc}\alpha_{o} & \alpha_{o s} \\ \alpha_{s o} & \alpha_{s}\end{array}\right], \quad B=\left[\begin{array}{cc}\beta_{o} & \beta_{o s} \\ \beta_{s o} & \beta_{s}\end{array}\right], \quad \varepsilon_{t-1}=\left[\begin{array}{cc}\varepsilon_{o, t-1} & \varepsilon_{o s, t-1} \\ \varepsilon_{s o, t-1} & \varepsilon_{s, t-1}\end{array}\right], \quad H_{t-1}=\left[\begin{array}{cc}h_{o, t-1} & h_{o s, t-1} \\ h_{s o, t-1} & h_{s, t-1}\end{array}\right]$

The diagonal lines of $A$ and $B$ matrices represent both variables' specific volatility, and off-diagonal elements capture the interactions of both variables; cross-volatility among variables. By doing matrix multiplication, we obtain three conditional variance and covariance equations as shown in the next page.

$$
\begin{aligned}
& H_{t}=\left[\begin{array}{cc}
\gamma_{o} & \gamma_{o s} \\
0 & \gamma_{s}
\end{array}\right]^{\prime}\left[\begin{array}{cc}
\gamma_{o} & \gamma_{o s} \\
0 & \gamma_{s}
\end{array}\right]+\left[\begin{array}{cc}
\alpha_{o} & \alpha_{o s} \\
\alpha_{s o} & \alpha_{s}
\end{array}\right]\left[\begin{array}{cc}
\varepsilon^{2}{ }_{o, t-1} & \varepsilon_{o, t-1} \varepsilon_{s, t-1} \\
\varepsilon_{s, t-1} \varepsilon_{o, t-1} & \varepsilon^{2}{ }_{s, t-1}
\end{array}\right]^{\prime}\left[\begin{array}{cc}
\alpha_{o} & \alpha_{o s} \\
\alpha_{s o} & \alpha_{s}
\end{array}\right]^{\prime}+ \\
& {\left[\begin{array}{cc}
\beta_{o} & \beta_{o s} \\
\beta_{s o} & \beta_{s}
\end{array}\right]\left[\begin{array}{cc}
h_{o, t-1} & h_{o s, t-1} \\
h_{s o, t-1} & h_{s, t-1}
\end{array}\right]\left[\begin{array}{cc}
\beta_{o} & \beta_{o s} \\
\beta_{s o} & \beta_{s}
\end{array}\right]^{\prime}} \\
& h_{o, t}=\gamma_{o}{ }^{2}+\alpha_{o}{ }^{2} * \varepsilon^{2}{ }_{o, t-1}+2 * \alpha_{o} * \alpha_{s o} * \varepsilon_{o, t-1} \varepsilon_{s, t-1}+\alpha_{s o}{ }^{2} * \varepsilon^{2}{ }_{s, t-1}+\beta_{o}{ }^{2} * h_{o, t-1}+2 * \beta_{o} * \beta_{s o} \\
& * h_{s o, t-1}+\beta_{s o}{ }^{2} * h_{s, t-1} \\
& h_{s, t}=\gamma_{s}{ }^{2}+\alpha_{o s}{ }^{2} * \varepsilon^{2}{ }_{o, t-1}+2 * \alpha_{o s} * \alpha_{s} * \varepsilon_{o, t-1} \varepsilon_{s, t-1}+\alpha_{s}{ }^{2} * \varepsilon^{2}{ }_{s, t-1}+\beta_{o s}{ }^{2} * h_{o, t-1}+2 * \beta_{o s} * \beta_{s} \\
& * h_{o s, t-1}+\beta_{s}{ }^{2} * h_{s, t-1} \\
& h_{s o, t}=\gamma_{o} * \gamma_{o s}+\alpha_{o} * \alpha_{o s} * \varepsilon^{2}{ }_{o, t-1}+\left(\alpha_{s o} \alpha_{o s}+\alpha_{o} \alpha_{s}\right) * \varepsilon_{o, t-1} \varepsilon_{s, t-1}+\alpha_{s o} * \alpha_{s} * \varepsilon^{2}{ }_{s, t-1}+\beta_{o} * \beta_{o s} \\
& * h_{o, t-1}+\left(\beta_{s o} \beta_{o s}+\beta_{o} \beta_{s}\right) * h_{o s, t-1}+\beta_{s o} * \beta_{s} * h_{s, t-1}
\end{aligned}
$$

First, we observed in Table 5 that the diagonal elements of matrix A $\left(\alpha_{o}\right.$ and $\left.\alpha_{s}\right)$ and matrix $\mathrm{B}\left(\beta_{o}\right.$ and $\left.\beta_{s}\right)$ are all significant, since these elements represent the own historical squared errors (shocks) and historical volatility of crude oil and S\&P500 index returns, respectively. They are sensitive to their own shocks and volatilities as we examined before with the univariate GARCH method. More important is, to look at offdiagonal elements of both $\mathrm{A}$ and $\mathrm{B}$ matrices to capture the shocks and the volatility spillovers between the variables. For instance, if we look at the historical shocks, the results show that $\alpha_{s o}$ is not significant whereas $\alpha_{o s}$ is significant at $10 \%$ level. This reflects that stock market returns (which was denoted by $s$ ) is not affected by "volatility surprises" that comes from the crude oil returns (denoted by $o$ ). However, S\&P500 index returns volatility affects the crude oil returns volatility based on significant historical squared residuals of $\alpha_{o s}$ at $10 \%$ significance level. When we check the historical covariance $\left(\beta_{\text {os }}\right.$ and $\left.\beta_{\text {so }}\right)$ in matrix $\mathrm{B}$, we recorded that $\beta_{o s}$ (the parameter that related with the spillover from stock market to crude oil) is significant at 5\% significance level. This means, the S\&P500 index stock market volatility affects the crude oil price returns. On the other hand, $\beta_{s o}$ is found to be not significant (with probability of 0.5603 ) which indicates that stock market volatility is not affected by the volatility of the crude oil. Results of BEKK-GARCH estimation show that there is unidirectional volatility spillovers (one way volatility transmission), and volatility spillovers are detected from S\&P500 index returns to crude oil price returns. In the opposite situation, we do not observe volatility transmission from crude oil returns to the S\&P500 index. On the other hand, we found bi-directional volatility spillover effect between crude oil price returns and S\&P500 index returns with univariate GARCH method. However, volatility transmissions are observed much more from S\&P500 index to crude oil returns than the opposite direction. By using more sophisticated volatility spillover technique (BEKK-GARCH); we found consistent results 
showing that there is volatility spillover effect from S\&P500 index returns to crude oil returns, but the model detected no spillover effect vice versa.

Table 5

Bivariate BEKK-GARCH - Volatility Spillover Effect

\begin{tabular}{ccccc}
\hline & Coefficient & Std. Error & Z-Statistic & Prob. \\
\hline \multicolumn{7}{c}{ Conditional Mean Estimates } & & \\
\hline$c_{o}$ & 0.000282 & 0.000329 & 0.856332 & 0.3918 \\
$c_{s}$ & $0.000602^{* *}$ & 0.000157 & 3.840333 & 0.0001 \\
$\theta_{\mathrm{o}}$ & $-0.028627^{* *}$ & 0.017363 & -1.648730 & 0.0092 \\
$\theta_{\mathrm{s}}$ & $-0.083564^{* *}$ & 0.020211 & -4.134512 & 0.0000 \\
\hline$\gamma_{o}$ & Conditional Variance-Covariance Estimates & & 0.918475 & 0.0000 \\
$\gamma_{s}$ & $0.001624^{* *}$ & 0.000235 & 3.040593 & 0.0024 \\
$\gamma_{o s}$ & $0.000624^{* *}$ & 0.000205 & -12.49196 & 0.0000 \\
$\alpha_{o}$ & $-0.001348^{* *}$ & 0.000108 & 22.94822 & 0.0000 \\
$\alpha_{o s}$ & $0.227140^{* *}$ & 0.009898 & 1.957039 & 0.0503 \\
$\alpha_{s o}$ & $0.040689^{*}$ & 0.020791 & 0.925169 & 0.3549 \\
$\alpha_{s}$ & 0.004241 & 0.004584 & 22.45139 & 0.0000 \\
$\beta_{o}$ & $0.318092^{* *}$ & 0.014168 & 429.7776 & 0.0000 \\
$\beta_{o s}$ & $0.972945^{* *}$ & 0.002264 & -2.402976 & 0.0163 \\
$\beta_{s o}$ & $-0.017259^{* *}$ & 0.007182 & -0.582341 & 0.5603 \\
$\beta_{s}$ & -0.001086 & 0.001865 & 187.1093 & 0.0000 \\
\hline
\end{tabular}

Note: $* *$ and $*$ denote statistically significant at 0.05 and 0.10 levels, respectively.

\section{Conclusion}

This paper has investigated the volatility transmission between the crude oil price returns and the U.S. S\&P500 index returns over the period 2006-2016. Focusing on the univariate GARCH method volatility transmission assessment; the obtained results indicate volatility spillover effects of S\&P500 index returns on the crude oil returns is more dominant than that of crude oil returns on the S\&P500 index returns. With multivariate GARCH model, we have found one-way volatility spillover effect that runs from S\&P500 index returns to crude oil returns. As BEKK parameterization of multivariate GARCH is more convenient to examine the volatility spillover, we conclude that there is a significant unidirectional volatility spillover effect that runs from S\&P500 index returns to the crude oil price returns. These findings are consistent with the results of recent research papers such as Wei and Chen (2014) and Özer (2017) since they underlined the significant effect of S\&P500 index returns on the crude oil price returns. The results that we obtained are important for understanding the nexus between crude oil price and stock market returns. These findings have implications for investors and oil-stock portfolio holders for their portfolio decisions in order to manage their risks on their international investments. This study suggests that crude oil investment participants should consider the information from U.S. stock market returns in order to predict the potential volatility in crude oil price returns and to perform their risk management more effectively. For the future research, the volatility spillover can be examined for other commodities and other financial markets which are affecting financial behavior of each other in order to consider the information transmissions within multivariate framework.

\section{References}

Ågren, M. (2006). Does oil price uncertainty transmit to stock markets? (No. 2006: 23). Working Paper.

Anand, B., Paul, S., \& Ramachandran, M. (2014). Volatility spillover between oil and stock market returns. Indian Economic Review, 37-56.

Arouri, M. E. H., \& Nguyen, D. K. (2010). Oil prices, stock markets and portfolio investment: evidence from sector analysis in Europe over the last decade. Energy Policy, 38(8), 4528-4539.

Baba, Y., Engle, R. F., Kraft, D. F., \& Kroner, K. F. (1990). Multivariate simultaneous generalized ARCH. Manuscript, University of California, San Diego, Department of Economics. 
Bollerslev, T. (1986). Generalized autoregressive conditional heteroskedasticity. Journal of econometrics, 31(3), 307-327.

Burbidge, J., \& Harrison, A. (1984). Testing for the effects of oil-price rises using vector autoregressions. International Economic Review, 25, 459-484.

Buyuksahin, B., \& Robe, M. A. (2012). Speculators, Commodities and Cross-Market Linkages. SSRN.

Chen, W., Hamori, S., \& Kinkyo, T. (2014). Macroeconomic impacts of oil prices and underlying financial shocks. Journal of International Financial Markets, Institutions and Money, 29, 1-12.

Ciner, C. (2001). Energy shocks and financial markets: nonlinear linkages. Studies in Nonlinear Dynamics \& Econometrics, 5(3), 203-212.

Ciner, C. (2013). Oil and stock returns: Frequency domain evidence. Journal of International Financial Markets, Institutions and Money, 23, 1-11.

Cong, R. G., Wei, Y. M., Jiao, J. L., \& Fan, Y. (2008). Relationships between oil price shocks and stock market: An empirical analysis from China. Energy Policy, 36(9), 3544-3553.

Creti, A., Joëts, M., \& Mignon, V. (2013). On the links between stock and commodity markets' volatility. Energy Economics, 37, 16-28.

Cuñado, J., \& de Gracia, F. P. (2003). Do oil price shocks matter? Evidence for some European countries. Energy economics, 25(2), 137-154.

El-Sharif, I., Brown, D., Burton, B., Nixon, B., \& Russell, A. (2005). Evidence on the nature and extent of the relationship between oil prices and equity values in the UK. Energy Economics, 27(6), 819-830.

Gomes, M., \& Chaibi, A. (2014). Volatility spillovers between oil prices and stock returns: A focus on frontier markets. Journal of Applied Business Research, 30(2), 509.

Jacquinot, P., Kuismanen, M., Mestre, R., \& Spitzer, M. (2009). An assessment of the inflationary impact of oil shocks in the euro area. The Energy Journal, 30(1), 49.

Jammazi, R., \& Aloui, C. (2010). Wavelet decomposition and regime shifts: Assessing the effects of crude oil shocks on stock market returns. Energy Policy, 38(3), 1415-1435.

Jones, C. M., \& Kaul, G. (1996). Oil and the stock markets. The journal of Finance, 51(2), 463-491.

Karunanayake, I., Valadkhani, A., \& O'Brien, M. J. (2009). Financial crises and stock market volatility transmission: evidence from Australia, Singapore, the UK, and the US.

Khalfaoui, R., Boutahar, M., \& Boubaker, H. (2015). Analyzing volatility spillovers and hedging between oil and stock markets: Evidence from wavelet analysis. Energy Economics, 49, 540-549.

Kilian, L., \& Park, C. (2009). The impact of oil price shocks on the US stock market. International Economic Review, 50(4), 1267-1287.

Kloner, D. (2001). The commodity futures modernization act of 2000. Securities Regulation Law Journal, 29(3), 286-297.

Lombardi, M. J., \& Ravazzolo, F. (2016). On the correlation between commodity and equity returns: implications for portfolio allocation. Journal of Commodity Markets, 2(1), 45-57.

Malik, F., \& Ewing, B. T. (2009). Volatility transmission between oil prices and equity sector returns. International Review of Financial Analysis, 3(18), 95-100.

Malik, F., \& Hammoudeh, S. (2007). Shock and volatility transmission in the oil, US and Gulf equity markets. International Review of Economics \& Finance, 16(3), 357-368.

Nazlioglu, S., Soytas, U., \& Gupta, R. (2015). Oil prices and financial stress: A volatility spillover analysis. Energy Policy, 82, 278-288.

Olson, M. (1988). The productivity slowdown, the oil shocks, and the real cycle. Journal of Economic Perspectives, 2(4), 43-69.

Özer, A. (2017). Volatility spillovers between oil prices and stock returns: Developed and Developing Countries Case. International Journal of Management Economics and Business, ICMEB17 Special Issue, 654-662.

Sadorsky, P. (1999). Oil price shocks and stock market activity. Energy economics, 21(5), 449-469.

Stoll, H. R., \& Whaley, R. E. (2009). Commodity Index Investing and Commodity Futures Prices. Nashville U.S.A: Vanderbilt University.

Wei, C. C., \& Chen, C. H. (2014). Does WTI Oil Price Returns Volatility Spillover to the Exchange Rate and Stock Index in the US?. International Journal of Energy Economics and Policy, 4(2), 189-197.

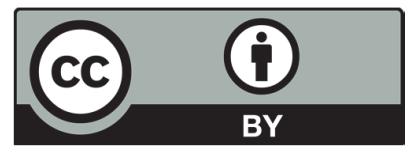

(C) 2019 by the authors; licensee Growing Science, Canada. This is an open access article distributed under the terms and conditions of the Creative Commons Attribution (CCBY) license (http://creativecommons.org/licenses/by/4.0/). 